\title{
ACCURACY OF MAIN-STREAM END-TIDAL CARBON DIOXIDE MEASUREMENT DURING THE ROAD TRANSPORT OF MECHANICALLY-VENTILATED PRETERM INFANTS
}

\author{
A. Abdelhamid ${ }^{1}$, N. Ratnavel ${ }^{2}$, A. Sinha ${ }^{2}$ \\ ${ }^{1}$ Neonatal Unit, University College of London, ${ }^{2}$ Neonatal Unit, London Neonatal Transfer Service, Barts and \\ The London Children's Hospital, Royal London Hospital, London, UK
}

Background: Non-invasive carbon dioxide $\left(\mathrm{CO}_{2}\right)$ monitoring in mechanically-ventilated preterm babies in the first few days of life is essential during neonatal stabilisation/transport. This helps to keep $\mathrm{CO}_{2}$ levels in an acceptable range avoiding the risks associated with hypo- and hypercarbia, and minimises repeated arterial sampling and its associated complications. End-tidal $\mathrm{CO}_{2}\left(\mathrm{EtCO}_{2}\right)$ monitoring is of value in identifying certain ventilation problems, and proven to be effective in children and adults. The reports of its use in neonates are controversial.

Objective: To assess the accuracy of measurements of $\mathrm{EtCO}_{2}$ during neonatal transport of mechanicallyventilated preterm infants as compared with the partial pressure of arterial $\mathrm{CO}_{2}\left(\mathrm{PaCO}_{2}\right)$ measurements collected simultaneously.

Design: Retrospective study on 221 paired $\mathrm{EtCO}_{2} / \mathrm{PaCO}_{2}$ recordings taken during stabilisation/road transport of 125 mechanically-ventilated PT infants. The paired $\mathrm{CO}_{2}$ values were compared and the differences between both were analysed. The Bland-Altman method was used to assess bias and repeatability.

Results: $\mathrm{EtCO}_{2}$ correlated significantly with $\mathrm{PaCO}_{2}$. However, the correlation was extremely poor $(\mathrm{r}=0.39$, $\mathrm{p}<0.0001,95 \%$ limits of agreement: $0.1996-0.4428) . \mathrm{EtCO}_{2}$ underestimated $\mathrm{PaCO}_{2}$ at a significant level (mean [SD] 2.595 [1.418] $\mathrm{kPa})$, and did not trend reliably over time within individual subjects $(\mathrm{r}=0.15$, $\mathrm{p}=0.12$ ). The $\mathrm{EtCO}_{2}$ bias was independent of the $\mathrm{PaCO}_{2}$ level range and lung disease severity in terms of gas exchange or shunting. After correction of $\mathrm{EtCO}_{2}$ with the mean bias, $58 \%$ of $\mathrm{EtCO}_{2}$ values fell within $1 \mathrm{kPa}$ of $\mathrm{PaCO}_{2}$ values.

Conclusions: $\mathrm{EtCO}_{2}$ has an unacceptable under-recording bias when compared to the simultaneous $\mathrm{PaCO}_{2}$ value. 